\section{Acute Appendicitis in Childhood}

SIR,-May I reply to some of the points which have been raised by correspondents following my article on "Parents, Family Doctors, and Acute Appendicitis in Childhood" (August 3, p. 277) ?

I was surprised to read the conclusion reached by Dr. F. R. Ryle (August 17, p. 442) as a result of reading this paper. Six months' concentrated experience of paediatrics in a combined medical and surgical unit would give an embryo family doctor sufficient experience of the acute abdomen in childhood to enable him to avoid most of the pitfalls in diagnosis. Fifty cases seen in six months might well be equivalent to twelve years of experience in family practice. To conclude, as Dr. Ryle does, that in order to achieve a better diagnostic level one must abandon the personal family doctor is an extraordinary assumption to make. I scarcely dare to think what the reactions of family doctors would have been if I had made this deduction from the evidence I presented.

I am grateful to Dr. B. P. Green (September 7, p. 622) for his kind comments. I am sorry that I cannot yet provide him with the figures of children who had normal appendices removed nor of children who were sent to hospital with possible appendicitis whose symptoms subsided rapidly. My analysis was done purely in order to elucidate the natural history of appendicitis, and other cases were therefore entirely excluded from it. As both Dr. Green and Dr. H. Simon (September 7, p. 622) point out, there are bound to be some children who come to hospital with a provisional label of appendicitis who are not operated on. This is because the question for the family doctor is not, "Does this child need a laparotomy ?" but whether the patient has got something sufficiently like appendicitis or is sufficiently ill to warrant observation in hospital. It is no slur on the capabilities of the family doctor that on occasions a laparotomy is not necessary-and it is important that hospital doctors should realize this. In the same way there is no need for family doctors to feel aggrieved because a hospital has managed a problem in a different way from that in which they originally expected it would be managed: the submission of a child to an anaesthetic and operation carries with it a risk (admittedly small), and also a subsequent degree of pain and discomfort, which in turn means that a child should not be operated on unless it is reasonably necessary. The fact that some children have to have an appendicectomy in a subsequent admission is the price that has to be paid in order to avoid unnecessary operations being carried out in the first admission.

Dr. Green comments that "other specialists could stake claims for the benefits of residence in general medicine. surgery, obstetrics, gynaecology, E.N.T. orthopaedics, etc." The basic subjects of medicine and surgery are covered by the requirements of the pre-registration year in hospital, and obstetrics is similarly covered, but as a third of the work that a family doctor does is concerned with children I would have thought that six months' experience in this subject would be more valuable than in some other specialties.

I was interested in Mr. E. E. O'Malley's comments (October 19, p. 998); I accept his point that on occasions there are times when the examination of a child can reveal minimal findings, and that therefore the history assumes a greater importance. Nevetheless. I still feel that the chils with an unusual history but definite physical findings is more common than a child with a typical history but minimal tenderness on examination.

Finally. Dr. J. P. Anderson (November 2, p. 1129) stresses the importance of diarrhoea, and I agree with his comments about how misleading it can be However. it was not possible for me to include data about the bowels and other clinical features because of lack of space. -I am. etc.

\section{The Children's Department. \\ The Royal Victoria Infirmary, \\ Newcastle upon Tyne.}

\section{Present State of Medicine}

SiR,-It appears from the procedure outlined in Dr. A. B. Davies's report to the B.M.A. Council (Supplement, November $16, p .162$ ) that no prompt action will follow upon the planned consultations and references, or that funds will be made available at reasonable speed to implement the final decisions. One cannot blame this upon any one individual, for the G.P. has nurtured this lengthy and indeterminate type of negotiation. What one deplores, however, is that delay is being encouraged by the present trend of thought on the improved status of the N.H.S. general practitioner.

It seems inseparable from this trend to start from the premise that the family doctor cannot aualify for a higher income from the N.H.S. unless he undertakes some form of hospital work either in or out of hospital and that his practice premises should be so eauinned. and it appears to me that it is from this attitude that it is regarded as necessary to take our consultant colleagues fully into confidence regarding G.P. remuneration and first of all win their approval to what is proposed. since the matter bears so closely upon their sphere of work.

In order to give the G.P. a contract on more flexible terms than at present, is it really necessary for him to drive a wedge into curative medicine based upon the hospitals ? It mav be that it is becoming more difficult to fill junior hosvital posts, but that is no argument for drafting the G.P. into hosnital: his work is proverly of quite a different type and only if he recognizes that and determines to stick to his own functions will the future clear and the family doctor service develop and flourish. His concern is the patient in the home. At the moment the G.P. is frustrated not only on the score of remuneration but also because his future and his scope of work are both uncertain and ill-defined. Everything worth while seems to end in hospital.

In order to re-establish the general practitioner in the Health Service the trend should rather be away from hospital, both the family doctor and the hospital doctor moving towards the community and the home. Whatever minor hospital service has to be done for the patient should be carried out not by the family doctor but by the hospital doctor who attends the centre at which a group of G.P.s hold their surgeries. Incidentally this would offer more scope for younger specialists whose way at present is blocked. Certainly the outdoor attendances at major hospitals would be relieved also.

The whole point is, is the Health Service to function as a curative medicine service, based on hospital, with the G.P. acting as a sort of extern, or is it to be a combined health and curative service based upon the community? Let us get that straight first and work backwards from there. Once that point is settled planning is simplified. It is by avoiding this, the essential issue, that we are getting bogged down. Personally having worked in both systems one vouches for the superiority of the latter system.

In fact at the present stage of consultation between committees and other bodies one is alarmed by the tilt of the Health Service towards curative medicine with its base in the big hospital, when it is patent that neither now nor in the future will the national exchequer be able to overtake the financial commitments of such a bias. A balance must be struck midway. What is the argument in favour of hospital centralization? Where is the mass of the insured persons? Certainly not in hospitals and surely there is no justice in over-spending on the few in hospital at the expense of the majority at home. By drafting the G.P. into hospital the balance will be further tilted against domiciliary medical care and against the community getting its fair share of the national money.-I am, etc.,

LEILA SUTHERLAND.

Crocketford, Dumfries.

SIR,-In three successive weeks doctors have written to you complaining that not once have their representatives on the local medical committee contacted them to ascertain their views on any particular subject. As a member of my local medical committee (and its predecessor, the local panel committee) for many, many years I am moved to reply, and I feel that I can speak for my fellow committee members.

We are not members for our own private gain; that should be obvious, for we are unpaid. Old and young, we are all busy practitioners who forfeit a whole afternoon away from our work every few weeks to do business voluntarily for 